\title{
Brief Analysis on the Cultivation of Positive Psychology for the Special College Student Group
}

\author{
Yujia Lei \\ Southwest University of Science and Technology, Mianyang Sichuan, 621000, China
}

Keywords: College students, Positive psychology, Cultivation

\begin{abstract}
The special college student group generally refers to the students whose families are financially difficult or who have some problems in learning, adaptation to college life, interpersonal communication. It is the massive educators' missions and wishes to help these students to mobilize their subjective factors, overcome their "problematic" mindset, and constantly improve their mental elasticity, so that they can build a social support system that is harmonious inside and outside and become the excellent successors with healthy personalities for the socialism with Chinese characteristics.
\end{abstract}

\section{Introduction}

After the survey and analysis of the ideological understanding levels and psychological health status of more than 100000 college students in a western province, the proportion of the students who felt depressed was $6.9 \%$, the proportion of the students who were nervous and anxious was 5.25\%, the proportion of the students who felt lonely was $7.02 \%$, and the proportion of the students who muddled along was $5.60 \%$. According to other statistics, the students who enjoyed the state-subsidized student loan in the central region accounted for $21 \%-22 \%$, and the students in the western region accounted for $27 \%$ - 29\%. The above objective data show that some college students' physical and psychological health has been affected severely due to the problems about economic position, learning, interpersonal communication and others for the socialization process. The key point of this paper is the education and guidance for these special students.

The special college student group has the unique psychological features because of the setbacks in the economic conditions, learning, or interpersonal adaptation and other aspects. On the one hand, they are independent, hard-working, diligent, and determined to become useful persons or own other positive qualities; however, on the other hand, due to the heavy economic burden, complicated interpersonal relationships, heavy learning task and their own high expectations, they bear double pressure: "survival" and "harmonious development", and have some psychological problems caused by above, such as low inferiority, self-closure, sensitive interpersonal relationship, somatization and extreme behaviors, which cause some negative impact on their learning, life, personality and other aspects. How to carry out the effective educational intervention according to the psychological characteristics of the special college students to maintain their positive psychology? The author tries to explore a new idea of ideological and political education from the perspective of positive psychology.

\section{The idea and main cognitive characteristics of positive psychology}

Positive psychology is a science to research the environment and process which can help individuals, groups and organizations to play the best state and functions, the idea of which is that people shall face and understand their own mental phenomena with a positive attitude and a vision of development, including many psychological problems and morbid psychology, and then motivate their existing or potential positive qualities and positive strength on this basis, so that people can feel the happiness of life, realize their social value actively, and do something consciously.

The main cognitive characteristic of the idea of positive psychology is the positive value 
orientation, which proposes that researchers shall focus on the research and cultivation of people's inherent positive potentials, look at people's potentials, motivations and abilities with a more open and appreciative view, pay attention to the health, courage, optimism, hope, happiness, faith, perseverance and so on, in order to make people feel really happy by actively cultivating and exploring people's positive strengthen [1]. To carry out the psychological health education for the special college students with the idea of positive psychology is to cultivate their positive psychological cognition, so that they can look at all the pressure in life and learning with a positive attitude, form the positive personalities, intensify the positive emotional experience and build a positive interpersonal support system, and then stimulate their individual potentials of mental elasticity.

\section{Improve the cognition of the special college student group from the perspective of positive psychology}

In the cognitive behavior theory, human emotions are not caused by induced events, but caused by the interpretation and evaluation of the individuals who experiences these events, and a same event will cause the individual to have positive or negative emotions and behaviors according to different interpretations. Because of many individual subjective and objective reasons, the special college student group often forms a pattern reaction of "event - trauma - problem". The inferiority, jealousy, anxiety and other negative emotions continuously intensify their behaviors to show some adverse reactions, such as autism, flinch and avoidance. If this vicious cycle often happens, they will suffer depression, anxiety, or aggressive personality characteristics.

In the research on positive psychology, Hill Son and Marie (1999) distinguished the positive personality characteristics from the negative personality characteristics based on the questionnaire, who thought there were two independent dimensionalities in the positive personality characteristics: one was the positive individualism (PI), and another was the positive relation with others (PR). PI means to accept the reality and self, be independent, have a personal life goal, or feel the meaning of life and success or other positive experience; PR means that when a person can be supported by others when he or she needs help, and he or she is able to help others when others need, who has satisfying and positive experience of interpersonal relationship ${ }^{[2]}$.

To guide the growth of special college student group from the perspective of positive psychology means to make them face and understand their situations and many mental phenomena (including psychological problems) correctly with their own inherent, potential and actually existing active power, virtue and kindness and a positive state (including psychological problems), so as to stimulate their own internal positive power and excellent quality. Compared with other college students, the special college students face more objective experiences in life, learning and interpersonal relationships that cannot be avoided. We shall help them to transform these experiences into the positive experience to gradually form the self-confidence, self-esteem and other personality traits, and carry out the continuous psychological health education and quality extension activities. For example, by the class meeting with thanksgiving as the theme, guide students to explain the poverty and other problems with positive viewpoints, regard all the difficulties as the test of life and rare spiritual wealth, and feel satisfied with "what they own"; release their negative emotions by the psychological guidance, and then they can write poems to the future and share them with others, explore and mobilize their own potentials, and stimulate their own positive emotional experience.

The positive emotional experience is the power and source for a person's positivity, optimism and self-confidence, which plays an important role in the building of individual coping strategies for pressure, makes individuals have more positive experience when responding to pressure, take more positive strategies, and reduce the passive and negative self-experience and coping strategies, explain the negative events with positive viewpoints, face the adversity positively, build confidence, be positive and enterprising, be grateful and kind to themselves and others. 


\section{Build a social support system actively for the special college student group}

Social support refers to the sum of free help for the socially disadvantaged group by some material and spiritual means in the social network. Generally speaking, it is the sum of all kinds of supports except the individuals, and a social behavior that is concomitant of the disadvantaged group. In the Contemporary Social Science Dictionary (1995), social support is regarded as an intimate connection between people, which can provide mental or material help for individuals when they face difficulties or threats, and is one of the intermediary factors between the psychosocial social pressure and the psychological disorder. From the perspective of the relationship between the social psychological stimulation and the individual psychological health, social support shall be defined as the influence that a person can get by social contact to relieve the psychological stress reaction and mental stress and improve the social adaptability. From the content of social support, Li Qiang (1998) thought that social support included three aspects: information support (to help the individuals to realize the events that trigger the difficulties and find out the resources and strategies to solve the difficulties), tool support (to provide practical service, financial support and special assistance), and emotional support (to make individuals feel their own value with care and comfort) (See Man, T. E., 1991).

According to related researches, as an important intervening variable, social support has some positive or negative influence on people's psychological health. If the special college students can experience more social support, they will have higher self-esteem, and then have more positive self-experience, which can help them improve their subjective well-being and the level of psychological health.

\subsection{The intimate family ties and family affection are the basis for building the social support}

The family has important and far-reaching influence on a person's personality formation and development. In the numerous social supports, the support from the family has the most extensive influence, which can last a lifetime. The early parental companion and the harmonious and intimate family ties have some influence on people's expression ability, communication ability, emotional stability and self-identity, which can drive the formation of healthy personality traits. The educators in colleges and universities shall guide students to keep or establish good emotional exchange and communication with their parents, and learn to express love and gratitude, because the family affection and love can nourish the soul, enhance the mental elasticity and keep a power for aggressiveness.

\subsection{The harmonious campus interpersonal relationship can strengthen the sense of social identity}

College life is an epitome of the society. Schoolmates come from different places, so they are different in life experience, family background, national culture and personality characteristic. The special college students have some difficulties in economic condition, learning or communication. If they don't build good campus interpersonal relationships, they don't have the sense of belonging, which will cause or exacerbate some psychological problems. Therefore, in the psychological education and daily ideological education in colleges and universities, we shall enhance the pertinence, set some targeted group coaching activities for the special group, enhance students' empathy experience and interpersonal interaction, in order to guide them to participate in some association activities or interest groups, expand their quality and enhance the social support, learn to build a good social support system, consciously experience and explore the resources of social support from the existing life to guarantee they have their own callable resources.

\subsection{Participate in the social practice or volunteering activities actively and experience the growth in the process of helping others}

Due to self-closure or avoidance of life, the special college students have less experience of active contacting with society and serving others. As time passes, they have no confidence in themselves and no empathy for others, and lack the intuitive understanding of society, which will inevitably lead 
them to look at the problems and things easily stubbornly or associate these problems with themselves. In the psychological health education for college students, while improving the healthy growth of students' psychology, we shall give them the opportunities to participate in the social practice, so that they can learn to be grateful and serve the society. Therefore, the educators in universities and colleges, especially the counselors, shall design some volunteering activities that are suitable for the special college students, or carry out some educative social practice and supported teaching activities in the winter and summer vacations, in order to let them actively participate in social service while understanding of social progress and development, feel their own value and roles, and constantly improve their self-efficacy and mental elasticity.

\section{Strengthen the resource construction of expansible psychological health education}

A college student with positive psychological traits will be harmonious and unified in the cognition, emotion, will, personality and other psychological traits. An excellent college student with good psychological quality is able to be a "self-actualizing man" (Maslow 1969) and a "fully-functional player" (Rogers, 1970), and fully feel the "sense of self-value” (Huang Xiting, 1997) [7]. The colleges and universities at all levels shall constantly innovate the concept of psychological health education, strengthen the course development of expansible psychological health education and the construction of network service platform.

The course of expansible psychological health education focuses on three themes: "quality development - self-growth", which follows the education at first and the basic principle of prevention first and quality promotion. The first is the cognitive psychological quality education course in the course design. This type of course is carried out mainly in the classroom, but its teaching method is the heuristic and interactive teaching, such as the case scenario simulation and the role experience and sharing, to improve students' cognition in mental phenomena, psychological traits, psychological adjustment and other aspects. The students who learn this type of course are the subjects, and the teachers are the promoters for students' learning. The course can encourage students to become the real cognitive subjects and feel the experience and growth by the three links "theme discussion knowledge introduction - scene reappearance".

The second is the activity psychological quality expansible course. On the one hand, this type of course is carried out for college students in the form of group activities, such as the group quality extension, friend and peer education and psychodrama, in order to expand students' psychological quality and improve their psychological environment; on the other hand, it is the group activity with college students as the subjects, such as the psychological quality promotion activity to take care of stay-at-home children, lonely old people and others, to drive students to put their knowledge into application, transform the knowledge into skills, enhance students' cognition of society while improving their psychology attainment, have empathy, and serve the society and others positively.

The forms of psychological health education shall be diversified. In the new media time that college students are crazy about, the network has become a "big classroom" to carry out the psychological education beyond the boundary of time and space. The network psychological education is the exploitation, utilization and regeneration of educational resources by the network. In the network psychological education, the network is the tool, environment, resource, content and system of psychological education. The rich resources of psychological education and information sharing are fast and economical, which are conducive to the extensive collection, rapid spread and timely extraction, and are convenient for the survey analysis and research of psychological education. Meanwhile, they are beneficial to the equal, free, comprehensive and timely psychological communication, and help the "netizens" to carry out the self-psychological education and improve their subjective expansibility. At present, China has established many service websites on psychological health, such as the psychological health education network, pchina.cn, and the online psychological health education for Chinese college and secondary school students. Colleges and universities shall take full advantage of campus network to expand the form and content of psychological health education, such as the establishment of psychological health education, online 
psychological counseling, online psychological test and other services in the campus network. On the one hand, they can help the popularization of psychological health knowledge; on the other hand, they can enhance the pertinence of psychological health education and expand the scope of services.

\section{Acknowledgements}

This paper is supported by the education management and reform research project of Southwest University of Science and Technology for the 2017th students. Project No.: 17sxb193. Project name: Research on the Cultivation of Political Identification of College Students in the New Media Environment.

\section{References}

[1] Li Qiang, Social Support and Individual Psychological Health, Tianjin Social Sciences, 1998, (1): 67.

[2] Zheng Xue, Positive Psychology, Beijing Normal University Publishing Group, 2016, 7 (1): 183.

[3] Zheng Xiangzhuan, Research on the Development of the Positive Personality of College Students in Local Colleges and Universities, Chinese Journal of Special Education, 2009 (6): 69-74.

[4] Li Yuan, On the Development Standard of the Psychological Health Education for College Students, Theory and Practice of Education, 2004 (7): 43-44. 